\title{
Primary aldosteronism in normokalemic patients with adrenal incidentalomas
}

Giampaolo Bernini, Angelica Moretti, Gianfranco Argenio and Antonio Salvetti

Department of Internal Medicine, University of Pisa, Pisa, Italy

(Correspondence should be addressed to G Bernini, Department of Internal Medicine, University of Pisa, Via Roma 67, 56100 Pisa, Italy; Email: g.bernini@med.unipi.it)

\begin{abstract}
Objective: Since primary aldosteronism has been reported in asymptomatic incidental adrenal masses (adrenal incidentalomas, AI), the aim of our study was to detect primary aldosteronism in normokalemic patients with $\mathrm{AI}$ and to verify whether a raised plasma aldosterone (ALD)/plasma renin activity (PRA) ratio may be useful for diagnosis.

Design: One-hundred and twenty-five normokalemic patients with solid AI (90 hypertensives and 35 normotensives) and 82 essential hypertensives (EH) were studied. Upright ALD and PRA determination was performed in all cases while patients with abnormal ALD/PRA ratios were submitted to confirmatory tests (saline infusion and captopril tests) for diagnosis of primary aldosteronism.

Methods: ALD and PRA were measured by specific radioimmunoassays.

Results: PRA values in AI hypertensives $(1.05 \pm 0.13 \mathrm{ng} / \mathrm{ml} / \mathrm{h})$ were lower than in AI normotensives $(1.14 \pm 0.14 \mathrm{ng} / \mathrm{ml} / \mathrm{h}, P<0.05)$ and in $\mathrm{EH}(1.68 \pm 0.15 \mathrm{ng} / \mathrm{ml} / \mathrm{h}, P<0.0001)$. The ALD/PRA ratio in AI hypertensives $(46.4 \pm 5.1)$ was higher than in AI normotensives $(30.7 \pm 5.8, P<0.03)$ and in $\mathrm{EH}(33.2 \pm 3.5)$. Four patients with $\mathrm{EH}$ and $2 \mathrm{AI}$ normotensive patients had elevated ALD/PRA ratios but normal responses to the suppressive tests, thus excluding diagnosis of primary aldosteronism. Eight patients with AI and hypertension had a high ALD/PRA ratio, and 7 of these were further studied: in 5 patients diagnosis of primary aldosteronism was well-established by dynamic tests, adrenal vein sampling or by surgery.

Conclusions: Primary aldosteronism in normokalemic patients with incidentally discovered adrenal masses was detected in 4 of all cases and in at least 5.5\% of those with hypertension. Consequently, these patients, particularly if hypertensive, need to be routinely studied to exclude this hormonal disease. Evaluation of the ALD/PRA ratio seems to be a simple and reliable test for diagnosis.
\end{abstract}

European Journal of Endocrinology 146 523-529

\section{Introduction}

The incidental discovery of adrenal masses (incidentalomas) is becoming a common clinical problem for the physician, above all when detection occurs in hypertensive patients in whom a causal relationship between adrenal mass and hypertension may exist. Interestingly, the prevalence of hypertension in patients with adrenal incidentalomas (AI) is higher than in the general population $(1-3)$. This finding has a possible explanation because the apparently nonfunctioning tumors may secrete catecholamines, cortisol and aldosterone (2, 4-9) causing diseases (pheochromocytoma, sub-clinical Cushing's syndrome and primary aldosteronism) responsible for secondary hypertension.

Primary aldosteronism (PA) is an uncommon cause of endocrine hypertension. The prevalence of PA was previously thought to be less than $1 \%$, above all in unselected hypertensive population (10-13). However, mainly as a result of improved diagnostic techniques, the prevalence of PA is now estimated to be more than $5 \%$ both in specialist referral centers (14-18) and also in a primary care setting $(19,20)$. PA in the classical form presents with aldosterone (ALD) excess, low plasma renin activity (PRA) and hypokalemia. However, several reports indicate that normokalemic PA constitutes the most common presentation of the disease, while the hypokalemic variant probably occurs only in the most severe cases $(14,15,18$, 20-25). For these reasons, detection of PA in patients with adrenal incidentalomas, who according to the criteria of the Italian Study Group on Adrenal Tumors are normokalemic $(1,2,4)$, is not surprising.

It is well-known that in screening patients for primary aldosteronism, PRA determination is not specific, although very sensitive, because of the influence of 
medication and the high prevalence of low renin essential hypertension (26). On the other hand, measurement of plasma and urinary ALD alone may likewise be insufficient to diagnose hypokalemic patients with PA, because ALD values are sometimes in the normal range $(25,27,28)$. To date, the best screening test for distinguishing patients with essential hypertension from those with possible PA is the ratio of plasma ALD level to PRA $(12,15,28-31)$.

The aim of the present study was to detect primary aldosteronism in normokalemic patients with solid AI and to verify if a raised ALD/PRA ratio may be useful for diagnosis.

\section{Materials and methods}

\section{Subjects}

Among patients referred to our Department for radiological adrenal abnormalities, we studied only those in whom the discovery was incidental. In addition, patients found to have cystic adrenal lesions, hypokalemia (present or past), high catecholamine levels, abnormal pituitary-adrenal axis function or excess of sexual hormones and androgen precursors were not included in the study. We performed this selection because both in cystic tumors and in masses secreting catecholamines, cortisol or androgens, detection of PA is obviously unlikely. Thus, we consecutively evaluated 125 normokalemic patients with solid AI (90 hypertensives and 35 normotensives). Detection of the mass, in the absence of signs or symptoms of adrenal dysfunction, had been obtained after ultrasonography performed for hepato-biliary $(n=58)$ and genitourinary $(n=47)$ disorders or for aspecific abdominal $(n=20)$ pain. Computed tomography (CT) confirmed a solitary or clearly delineated nodule with a normalappearing contralateral gland in 93 cases (right side $n=59$, left side $n=34$; maximum diameter 26.8 \pm $1.04 \mathrm{~mm}$ (mean \pm S.E.), range $10-80 \mathrm{~mm}$ ). CT showed bilateral lesions in 32 cases: bilateral nodules $(n=8)$, enlargement $(>15 \mathrm{~mm})$ of both adrenals $(n=12)$ and monolateral enlargement associated with contralateral mass $(n=12)$.

Eighty-two essential hypertensives (EH) were also studied, chosen among patients referred to our Department. Diagnosis had been established after exclusion, by appropriate biochemical and morphological investigations, of all detectable causes of hypertension. Hypokalemia had never been documented in these patients and in no case had abdominal ultrasonography $(n=$ $75)$ or CT $(n=7)$ shown adrenal masses. The patients had been followed-up for at least 1 year and their blood pressure was well controlled with conventional antihypertensive treatment.

Demographic and clinical data of our 207 patients are given in Table 1.

\section{Experimental design}

Patients taking drugs (anti-hypertensive or other drugs) suspended medication for at least 2 weeks prior to the study. All patients maintained their usual diet without salt restriction (31). Patients presented between 0800 and $0900 \mathrm{~h}$ in the morning, after overnight fasting. Twenty-four-h urine was collected for sodium, potassium and aldosterone determination. Blood samples for sodium, potassium, ALD and PRA measurements were obtained in patients who had been standing for at least $1 \mathrm{~h} \mathrm{(32)}$.

The ALD/PRA ratio cut-off in our laboratory is 112 . This value represents the $95 \%$ upper confidence limit of the 90th percentile of normal values obtained from patients with EH (mean \pm s.D. 33.2 \pm 3.5 , median 19.72, range 3.72-166.5). Therefore, patients with AI and an ALD/PRA ratio over 112 underwent confirmatory tests in order to demonstrate unsuppressibility of plasma ALD levels $(33,34)$. In this case, prior to testing the patients underwent controlled salt intake $(80-100 \mathrm{mmol} /$ day sodium and $60-80 \mathrm{mmol} /$ day potassium), in addition to pharmacological wash-out. Subsequently, saline infusion (plasma ALD determination before and after 2 liters of normal saline i.v. over a 4-h period) and the captopril test (plasma ALD measurements before and $2 \mathrm{~h}$ after captopril $50 \mathrm{mg}$

Table 1 Demographic data of essential hypertensives $(\mathrm{EH})$ and of patients with adrenal incidentaloma (Al) both hypertensive and normotensive. Mean values \pm S.E. and range (in parentheses) are reported.

\begin{tabular}{lccc}
\hline & & \multicolumn{2}{c}{ Adrenal incidentalomas } \\
\cline { 3 - 4 } & EH $(n=82)$ & Hypertensive $(n=90)$ & Normotensive $(n=35)$ \\
\hline Sex $(\mathrm{M} / \mathrm{F})$ & $48 / 34$ & $30 / 60$ & $12 / 23$ \\
Age (years) & $47.0 \pm 1.4(16-68)$ & $59.7 \pm 1.1^{* *}(31-86)$ & $54.7 \pm 2.2^{*}(26-80)$ \\
BMl $\left(\mathrm{kg} / \mathrm{m}^{2}\right)$ & $28.5 \pm 0.5$ & $26.3 \pm 0.4 \dagger$ & $26.2 \pm 1.0 \dagger$ \\
SBP $(\mathrm{mmHg})$ & $153.8 \pm 1.7$ & $158.8 \pm 1.4$ & $124.1 \pm 1.8 \ddagger$ \\
DBP $(\mathrm{mmHg})$ & $97.6 \pm 0.9$ & $97.3 \pm 0.9$ & $78.5 \pm 1.0 \ddagger$ \\
\hline
\end{tabular}

$\mathrm{BMI}$, body mass index; SBP, systolic blood pressure; DBP, diastolic blood pressure.

${ }^{*} P<0.0004$ and ${ }^{* *} P<0.0001$ vs $\mathrm{EH} ; \dagger P<0.007$ vs $\mathrm{EH} ; \ddagger P<0.0001$ vs $\mathrm{EH}$ and Al hypertensives. 
orally) were performed. ALD values above $15 \mathrm{ng} / \mathrm{dl}$ after captopril administration were considered a typical feature of PA $(35,36)$. As far as salt loading is concerned, it is well known that normal subjects and essential hypertensives suppress plasma ALD below $5 \mathrm{ng} / \mathrm{dl}(18,33,37,38)$, while patients with PA fail to suppress plasma ALD below $10 \mathrm{ng} / \mathrm{dl}(20,39,40)$. Patients in whom plasma ALD ranges between 5 and $10 \mathrm{ng} / \mathrm{dl}$ after saline infusion may have PA (41-43). For this reason the patients in the present study who showed a highly suspicious ALD post-loading response were further studied by adrenal vein sampling $(23,44$, $45)$.

The study was approved by the Local Ethical Committee and the patients gave their informed consent.

\section{Assays}

Plasma and urinary sodium and potassium were evaluated by photometry assay. Plasma samples for PRA and ALD determinations were collected in chilled anticoagulated glass tubes, immediately centrifuged and frozen at $-20^{\circ} \mathrm{C}$. Hormones were then assayed in duplicate and in the same run by specific RIAs. Intra-assay and interassay coefficients of variation were as follows: ALD (DiaSorin, Saluggia, Italy) 9.7\% and $11.5 \%$, PRA (DiaSorin) $7.6 \%$ and $9.1 \%$ respectively. Detection limits of the methods were below $2 \mathrm{ng} / \mathrm{dl}$ for ALD and below $0.2 \mathrm{ng} / \mathrm{ml} / \mathrm{h}$ for PRA. Cortisol (Immunotech International, Marseille, France), expressed in $\mathrm{ng} / \mathrm{ml}$, had intra-assay and interassay coefficients of variation of $5.7 \%$ and $6.6 \%$ respectively, and the sensitivity was $13 \mathrm{nmol} / \mathrm{l}$.

Blood pressure was recorded by mercury sphygmomanometer following recent guidelines (46).

\section{Statistical analysis}

PRA values and the ratio of plasma ALD to PRA were calculated with renin activity taken to be $0.2 \mathrm{ng} / \mathrm{ml} / \mathrm{h}$ in those patients where this value was below the sensitivity limit of our assay. Variables are expressed as mean, standard error and range. Krunskal-Wallis and Wilcoxon tests were performed for each variable to compare groups. The unpaired $t$-test was also used, when appropriate. Finally, Spearman correlation coefficients were adopted as parameters of associations. $P$ levels lower than 0.05 were considered statistically significant.

\section{Results}

Patients with adrenal incidentalomas, both normotensive and hypertensive, were older and leaner than EH. Systolic and diastolic blood pressure in AI normotensives was, by definition, lower than in AI hypertensives and in EH (Table 1).

As shown in Table 2, while plasma potassium did not significantly differ, patients with AI showed PRA values lower than $\mathrm{EH}$. This finding was more evident in the AI hypertensive subgroup which, consequently, showed the highest ALD/PRA ratio.

In no group was a correlation found between plasma ALD/PRA ratio and age, body mass index, blood pressure, plasma potassium or tumor size (in the patients with $\mathrm{AI})$.

Analytical data (Fig. 1) indicated that 4 patients with $\mathrm{EH}$ and 2 patients with AI and normal blood pressure had an ALD/PRA ratio that was borderline or over 112. When submitted to saline loading and the captopril test these patients (with urinary and upright plasma ALD lower than $30 \mu \mathrm{g} / 24 \mathrm{~h}$ and $30 \mathrm{ng} / \mathrm{dl}$ respectively) had normally suppressed plasma ALD levels. Thus they were false positives.

Eight patients with $\mathrm{AI}$ and hypertension $(8.8 \%)$ were found to have an ALD/PRA ratio above the normal value. As expected, they had significantly lower PRA values and a significantly higher plasma ALD and ALD/PRA ratio than the remaining group $(n=82)$, without difference in age, blood pressure, body mass index, plasma potassium or mass size (Table 3). Among these eight patients with abnormal ALD/PRA ratios (Table 4), six were further investigated by the salt loading and captopril tests: two patients showed normal responses whereas ALD unsuppressibility or partial suppressibility was found in 4 cases. One patient (no. 3) with a clear monolateral nodule was surgically treated and cured. Three patients (nos 1, 2 and 4) with bilateral adrenal enlargement underwent successful (at

Table 2 Plasma humoral data of essential hypertensives $(\mathrm{EH})$ and of patients with adrenal incidentaloma (AI) both hypertensive and normotensive. Mean values \pm S.E. are reported.

\begin{tabular}{lccc}
\hline & & \multicolumn{2}{c}{ Adrenal incidentalomas } \\
\cline { 3 - 4 } & EH $(n=82)$ & Hypertensive $(n=90)$ & Normotensive $(n=35)$ \\
\hline Plasma K $(\mathrm{mEq} / \mathrm{l})$ & $3.97 \pm 0.02$ & $4.05 \pm 0.03$ & $4.0 \pm 0.1$ \\
$\mathrm{ALD}(\mathrm{ng} / \mathrm{dl})$ & $31.1 \pm 1.7$ & $23.0 \pm 1.4^{*}$ & $19.9 \pm 1.9^{\star}$ \\
$\mathrm{PRA}(\mathrm{ng} / \mathrm{ml} / \mathrm{h})$ & $1.68 \pm 0.15$ & $1.05 \pm 0.13 \dagger \dagger$ & $1.14 \pm 0.14 \dagger \ddagger$ \\
ALD/PRA ratio & $33.2 \pm 3.5$ & $46.4 \pm 5.1 \S$ & $30.7 \pm 5.8$ \\
\hline
\end{tabular}

${ }^{\star} P<0.0005$ vs $\mathrm{EH} ; \dagger P<0.04$ and $\dagger \dagger P<0.0001$ vs $\mathrm{EH} ; \ddagger P<0.05$ vs Al hypertensives; $\S P<0.03$ vs Al normotensives. 


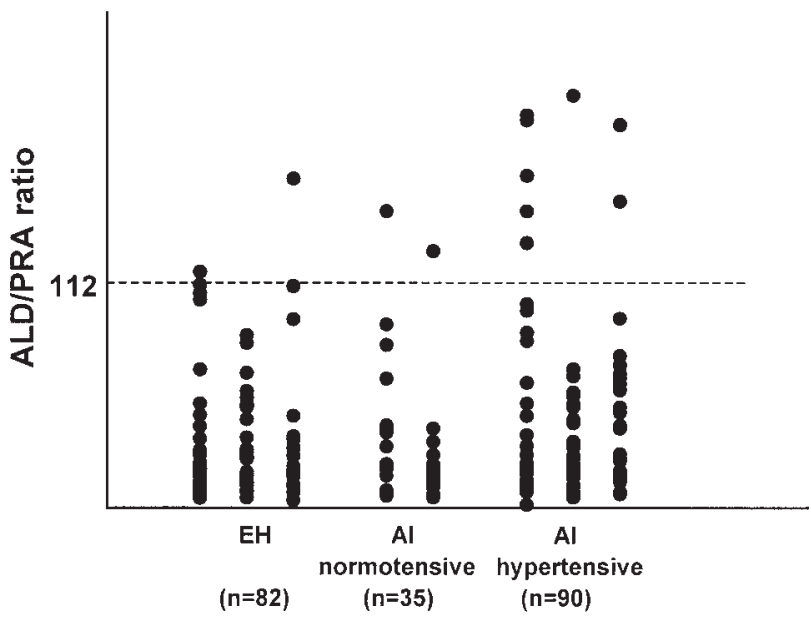

Figure 1 Individual data of the plasma ALD/PRA ratio in essential hypertensives $(\mathrm{EH})$ and in patients with adrenal incidentaloma $(\mathrm{Al})$ both hypertensive and normotensive. The dashed line indicates the upper $95 \%$ limit of normal values (112).

least 3-fold plasma cortisol elevation in the adrenal vein in comparison with the inferior vena cava) adrenal vein sampling $(23,44,45)$ which revealed an ALD/cortisol index that was similar in both sides $(<2)$ and greater than in the inferior vena cava (Table 5). This procedure allowed diagnosis and etiology of PA, i.e. bilateral adrenal hyperplasia. The seventh patient, without testing, underwent surgery for radiological features of the mass suspected of malignancy: one year later blood pressure, plasma ALD and ALD/PRA ratios were maintained in the normal range. The eighth patient dropped out. Thus, in 5 out of 7 patients studied, the diagnosis of PA was well-established. Overall, primary aldosteronism was found in $4.0 \%$ of all $\mathrm{AI}$ and in $5.5 \%$ of those
Table 3 Demographic, humoral and clinical data of adrenal incidentaloma hypertensives with plasma ALD/PRA ratio lower $(n=82)$ and higher $(n=8)$ than 112 . Mean values \pm S.E. are reported.

\begin{tabular}{|c|c|c|}
\hline & \multicolumn{2}{|c|}{ ALD/PRA ratio } \\
\hline & $<112$ & $>112$ \\
\hline $\operatorname{Sex}(M / F)$ & $28 / 54$ & $2 / 6$ \\
\hline Age (years) & $59.9 \pm 1.1$ & $57.1 \pm 2.8$ \\
\hline BMI $\left(\mathrm{kg} / \mathrm{m}^{2}\right)$ & $26.1 \pm 0.3$ & $27.8 \pm 1.2$ \\
\hline $\mathrm{SBP}(\mathrm{mmHg})$ & $159.0 \pm 1.4$ & $155.7 \pm 4.3$ \\
\hline $\mathrm{DBP}(\mathrm{mmHg})$ & $97.4 \pm 0.9$ & $95.7 \pm 3.4$ \\
\hline Mass side: M/B & $58 / 24$ & $5 / 3$ \\
\hline Mass size $(\mathrm{mm})^{\circ}$ & $26.8 \pm 1.3$ & $29.5 \pm 7.4$ \\
\hline Plasma K (mEq/l) & $4.0 \pm 0.03$ & $3.99 \pm 0.1$ \\
\hline ALD (ng/dl) & $21.5 \pm 1.4$ & $38.2 \pm 4.1^{\star *}$ \\
\hline PRA (ng/ml/h) & $1.13 \pm 0.14$ & $0.21 \pm 0.01^{*}$ \\
\hline
\end{tabular}

${ }^{*} P<0.05 ;{ }^{* *} P<0.0004$.

BMI, body mass index: SBP/DBP, systolic/diastolic blood pressure; ${ }^{\circ}$ Maximum diameter; $\mathrm{M}$, monolateral; $\mathrm{B}$, bilateral (bilateral nodules or bilateral enlargement of adrenals or increased thickness of one adrenal associated with a mass in the contralateral gland).

with hypertension. These results are shown in diagramatic form in Fig. 2.

\section{Discussion}

Our results show that patients in whom an adrenal mass has been incidentally detected, above all if they are hypertensive, need to be screened for primary aldosteronism even in the presence of normal potassium levels. Thus, $8.8 \%$ of our patients with AI and hypertension showed an abnormal ALD/PRA ratio and at least $5.5 \%$ had proven hyperaldosteronism. Although apparently similar to that found in the general

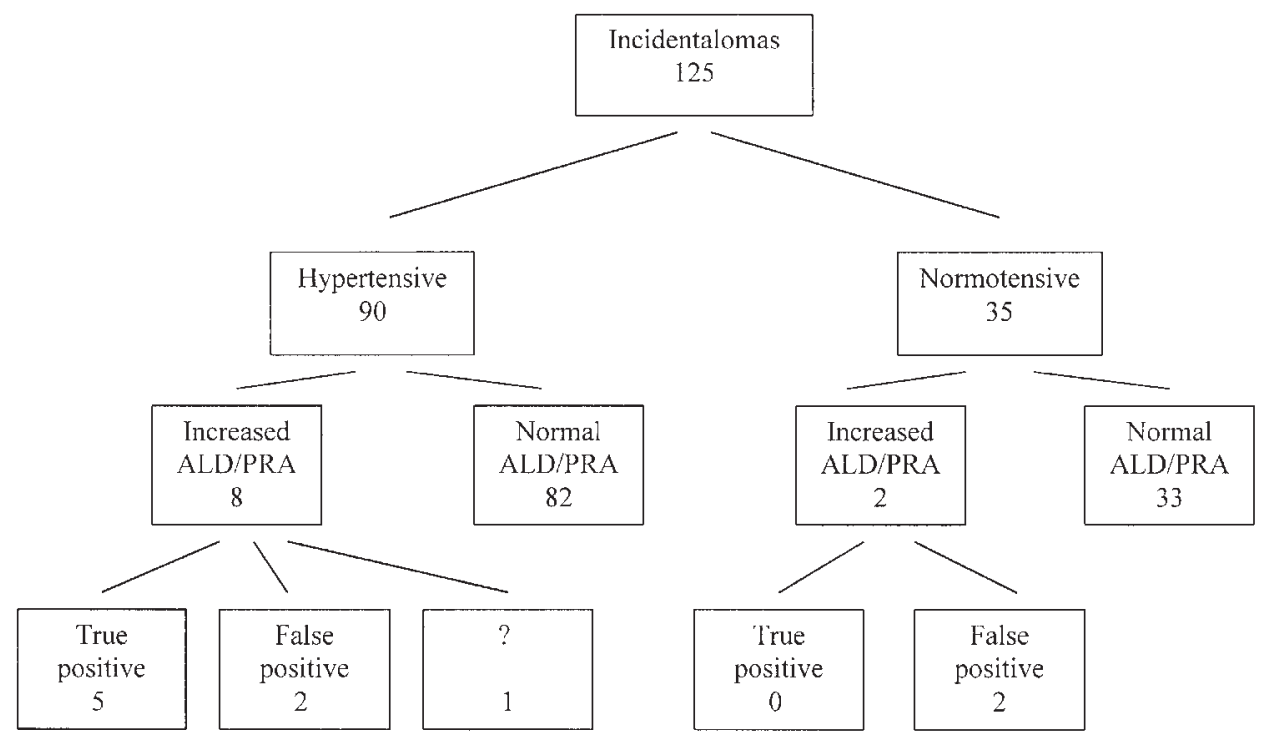

Figure 2 True positive and false positive results found in patients with adrenal incidentaloma. 
Table 4 Clinical data of adrenal incidentaloma hypertensives with probable primary aldosteronism (ALD/PRA ratio >112).

\begin{tabular}{|c|c|c|c|c|c|c|c|c|}
\hline & \multicolumn{8}{|c|}{ Patient } \\
\hline & 1 & 2 & 3 & 4 & 5 & 6 & $7^{*}$ & 8 \\
\hline $\mathrm{BP}(\mathrm{mmHg})$ & $160 / 90$ & $152 / 82$ & $176 / 108$ & $160 / 108$ & $140 / 90$ & $160 / 104$ & $138 / 94$ & $160 / 90$ \\
\hline Plasma K (mEq/l) & 4.0 & 4.0 & 4.1 & 3.9 & 4.7 & 3.8 & 3.7 & 3.8 \\
\hline Urinary $\mathrm{Na}(\mathrm{mEq} / 24 \mathrm{~h})$ & 119 & 119 & 24 & 196 & 104 & 86 & 70 & 90 \\
\hline Plasma ALD (ng/dl) & 30.0 & 26.8 & 33.6 & 41.7 & 39.2 & 39.7 & 63.9 & 31 \\
\hline Urinary ALD ( $\mu \mathrm{g} / 24 \mathrm{~h})$ & 32.1 & 33.6 & 35 & 31.7 & 35.8 & 29 & 52.3 & 46.2 \\
\hline PRA (ng/ml/h) & 0.2 & 0.2 & 0.2 & 0.2 & 0.2 & 0.2 & 0.33 & 0.2 \\
\hline ALD/PRA ratio & 150 & 134 & 168 & 208 & 196 & 198 & 194 & 155 \\
\hline Mass size $(\mathrm{mm})$ & 24 & 25 & 24 & 10 & 28 & 20 & 25 & 80 \\
\hline Mass side (L/R/B) & B & B & L & B & $\mathrm{R}$ & $\mathrm{R}$ & $\mathrm{L}$ & $\mathrm{L}$ \\
\hline Salt loading: ALD nadir vs basal (ng/dl) & 8 vs 21 & 8 vs 26 & 16 vs 25 & 11 vs 31 & 4 vs 27 & 1 vs 24 & nd & nd \\
\hline Captopril test: ALD nadir vs basal (ng/dl) & 20 vs 31 & 27 vs 32 & 22 vs 29 & 16 vs 30 & 13 vs 26 & 6 vs 27 & nd & nd \\
\hline
\end{tabular}

BP, blood pressure; L, left; R, right; B, bilateral; nd, not done.

* The patient underwent surgery. One year after the removal of adrenal mass, clinical and humoral data were as follows: plasma ALD 5.4 ng/dl, PRA $0.48 \mathrm{ng} / \mathrm{ml} / \mathrm{h}$, ALD/PRA ratio 11.2, urinary ALD $11.3 \mu \mathrm{g} / 24 \mathrm{~h}$, urinary $\mathrm{Na} 75 \mathrm{mEq} / 24 \mathrm{~h}$, plasma K $4.0 \mathrm{mEq} / 1$, blood pressure $118 / 74 \mathrm{mmHg}$

hypertensive population $(29,32,47)$, this percentage is in effect higher since patients with hypokalemia are usually included among unselected hypertensives, while the present data were obtained in normokalemic subjects only.

Detection of primary aldosteronism in patients with AI has already been reported, with values ranging between $1.6 \%$ (2) and $3.0 \%$ (9). The number we found is even greater, probably because we selected only solid tumors after excluding glucocorticoid, sex steroid or catecholamine excess, while in the above reported series all AI (normo- and hyper-functioning, solid and cystic tumors) were studied.

As is known, the clinical and humoral features of PA are not always pathognomonic of the disease: plasma and urinary ALD may be in the normal range (25, 27,28 ) and low PRA values are detected in patients with essential hypertension (26). In addition, serum potassium is frequently normal $(14,15,18,20-25)$ and even documented cases of normotensive patients with PA have been reported (48-50). On the basis of these findings, use of the plasma ALD/PRA ratio is believed, to date, to be the best screening test for primary aldosteronism $(12,15,18,28-31)$. This test is very accurate, simple, does not require the inconvenience of urine collection and does not seem to be influenced by variations in sodium intake, total body potassium deficit or by the drugs used to treat hypertension, with the exception of spironolactone
$(29,31)$. Therefore, ALD/PRA ratio determination may be useful in the work-up of AI since the number of unexpectedly detected adrenal masses is constantly increasing, due to the growing spread of radiological procedures (51-54). Management of AI now includes not only a morphological study in order to rule out malignant tumors (52-54), but also hormonal screening because of the possible occurrence of abnormalities in glucocorticoid, catecholamine, sex steroid or mineralocorticoid secretion $(2,4-9)$. This hormonal evaluation is particularly indicated in hypertensive patients in whom high blood pressure values may be related to endocrine dysfunction of the adrenal glands. It is interesting to note that the prevalence of hypertension in patients with AI is higher than in the general population (1-3). This finding may suggest a possible pathogenetic link between hypertension and adrenal mass. However, in order to avoid the 'cascade-effect' in the clinical care of patients with AI, several restrictive diagnostic work-ups have been proposed to identify hormonal diseases. As far as primary aldosteronism is concerned, many authors claim that since the prevalence of the disease is low it may be counterproductive to extensively screen all patients with AI (even if they are hypertensive), while it is preferable to perform specific evaluations only in the presence of hypokalemia (52, 54-56). Our results show that high blood pressure values, more than plasma potassium levels, are crucial in alerting physicians to the suspicion of primary

Table 5 Results of bilateral adrenal vein sampling in the three patients with bilateral adrenal enlargement, ALD/PRA ratio over 112 and partial ALD post loading response. Results are expressed as ALD in $\mathrm{ng} / \mathrm{dl} / \mathrm{cortisol} \mathrm{in} \mathrm{ng} / \mathrm{ml}$.

\begin{tabular}{lccc}
\hline Patient & Right side ALD/cortisol & Lift side ALD/cortisol & Peripheral ${ }^{\star}$ ALD/cortisol \\
\hline 1 & $380 / 680$ & $290 / 587$ & $30 / 130$ \\
2 & $193 / 391$ & $230 / 724$ & $26 / 92$ \\
4 & $272 / 1060$ & $236 / 980$ & $41 / 196$ \\
\hline
\end{tabular}

* Infrarenal portion of inferior vena cava. 
aldosteronism in patients with AI. Significantly, no patient with PA was found in AI normotensives. We therefore suggest that in the diagnostic work-up of patients with AI and normal blood pressure, evaluation of the renin-angiotensin-aldosterone system may be avoided.

We are aware that the selection of our patients did not allow us to establish the prevalence of primary aldosteronism in AI. However, the study was not undertaken for this specific purpose, but rather to assess the presence of this form of endocrine hypertension and, therefore, to point out that in patients with solid AI normal potassium levels do not exclude the diagnosis of primary aldosteronism. Therefore, only focusing on primary aldosteronism in hypokalemic adrenal incidentaloma patients overlooks a significant subset of primary aldosteronism patients who could be cured of their hypertension if it were detected by a cost-effective screening tool such as the plasma ALD/PRA ratio.

In the choice of our ALD/PRA ratio cut-off we took many factors into account. First, the lower limit of PRA was moved to $0.2 \mathrm{ng} / \mathrm{ml} / \mathrm{h}$ (the sensitivity limit of our assay) in those patients where this value was below. Secondly, since low renin levels are frequently observed in EH (26), the cut-off was obtained from a large number of patients with well-ascertained essential hypertension instead of from normotensive controls, in order to avoid the high number of false positive results in EH (13). Finally, the evaluation was made in conditions similar to those of patients with AI (pharmacological wash-out, free salt intake, upright position before testing). In these conditions our cut-off proved to be higher than that reported by other centers (12, $28,29,31)$. This variability is not surprising, due both to different assay techniques and laboratory conditions and the influence of several variables on PRA and ALD levels. Consequently, the importance of locally validated criteria for establishing the normal range must be stressed.

In conclusion, the present data show that in normokalemic patients with incidentally discovered adrenal masses primary aldosteronism is detectable. Therefore, at least the hypertensive patients with AI need to be routinely studied to exclude this hormonal disease. Evaluation of the ALD/PRA ratio seems to be a simple and reliable test for diagnosis.

\section{Acknowledgements}

We wish to thank P Duranti, M Rocchi and R Santoni for their precious technical assistance.

\section{References}

1 Angeli A, Osella G, Ali' A \& Terzolo M. Adrenal incidentaloma: an overview of clinical and epidemiological data from the National Italian Study Group. Hormone Research 199747 279-283.
2 Mantero F, Terzolo M, Arnaldi G, Osella G, Masini AM, Ali' A et al. A survey on adrenal incidentaloma in Italy. Journal of Clinical Endocrinology and Metabolism 200085 637-644.

3 Russell RP, Masi AT \& Richter ED. Adrenal cortical adenomas and hypertension: a clinical pathologic analysis of 690 cases with matched controls and a review of the literature. Medicine 1972 $51211-225$.

4 Mantero F, Masini AM, Opocher G, Giovagnetti M \& Arnaldi G. Adrenal incidentaloma: an overview of hormonal data from the National Italian Study Group. Hormone Research $199747284-289$.

5 Reincke M, Nieke J, Krestin GP, Saeger W, Allolio B, Winkelmann W et al. Preclinical Cushing's syndrome in adrenal incidentalomas: comparison with adrenal Cushing's syndrome. Journal of Clinical Endocrinology and Metabolism 199275 826-832.

6 Osella G, Terzolo M, Borretta G, Magro G, Ali’ A, Piovesan A et al. Endocrine evaluation of incidentally discovered adrenal masses (incidentalomas). Journal of Clinical Endocrinology and Metabolism $1994791532-1539$.

7 Ambrosi B, Peverelli S, Passini E, Re T, Ferrario R, Colombo P et al. Abnormalities of endocrine function in patients with clinically silent adrenal masses. European Journal of Endocrinology 1995 $132422-428$.

8 Terzolo M, Osella G, Ali' A, Borretta G, Magro GP, Termine A et al. Different pattern of steroid secretion in patients with adrenal incidentaloma. Journal of Clinical Endocrinology and Metabolism $199681740-744$.

9 Barzon L, Scaroni C, Sonino N, Fallo F, Gregianin M, Macri' C et al. Incidentally discovered adrenal tumors: endocrine and scintigraphic correlates. Journal of Clinical Endocrinology and Metabolism $19988355-62$.

10 Conn JW, Cohen EL, Rovner DR \& Nesbit RM. Normokaliemic primary aldosteronism. A detectable cause of curable essential hypertension. Journal of the American Medical Association 1965 $193200-206$.

11 Tucker RM \& Labarthe DR. Frequency of surgical treatment for hypertension in adults at the Mayo Clinic from 1973 to 1975. Mayo Clinic Proceedings 197752 549-555.

12 Blumenfeld JD, Sealey JE, Schlussel Y, Vaughan ED Jr, Sos TA, Atlas SA et al. Diagnosis and treatment of primary hyperaldosteronism. Annals of Internal Medicine 1994121 877-885.

13 Ganguly A. Primary aldosteronism. New England Journal of Medicine $19983391828-1834$.

14 Gordon RD, Zlesak MD, Tunny J, Stowasser M \& Klemm SA. Evidence that primary aldosteronism may not be uncommon: $12 \%$ incidence among antihypertensive drug trial volunteers. Clinical and Experimental Pharmacology and Physiology 199320 296-298.

15 Gordon RD, Stowasser M, Tunny TJ, Klemm SA \& Rutherford JC. High incidence of primary aldosteronism in 199 patients referred with hypertension. Clinical and Experimental Pharmacology and Physiology 199421 315-318.

16 Kumar A, Lall SB, Ammini A, Peshin SS, Karmarkar MG, Talwar KK et al. Screening of a population of young hypertensives for primary hyperaldosteronism [correspondence]. Journal of Human Hypertension $19948731-732$.

17 Lim PO, Brennan G, Shields P. In Unexpectedly high prevalence of primary aldosteronism in a hypertensive population in Dundee. Edinburgh: British Endocrine Society, 1998.

18 Fardella CE, Mosso L, Gomez-Sanchez C, Cortes P, Soto J, Pinto LGM et al. Primary hyperaldosteronism in essential hypertensives: prevalence, biochemical profile, and molecular biology. Journal of Clinical Endocrinology and Metabolism 200085 1863-1867.

19 Lim PO, Rodgers P, Cardale K, Watson AD \& MacDonald TM. Potentially high prevalence of primary aldosteronism in a primary-care population. Lancet 199935340.

20 Loh K-C, Koay ES, Khaw M-C, Emmanuel SC \& Young WF. Prevalence of primary aldosteronism among Asian hypertensive patients in Singapore. Journal of Clinical Endocrinology and Metabolism 200085 2854-2859.

21 Gordon R. Mineralocorticoid hypertension. Lancet 1994344 $240-243$. 
22 Mulatero P, Veglio F, Pilon C, Rabbia F, Zocchi C, Limone P et al. Diagnosis of glucocorticoid-remediable aldosteronism in primary aldosteronism: aldosterone response to dexamethasone and long polymerase chain reaction for chimeric gene. Journal of Clinical Endocrinology and Metabolism $1998 \mathbf{8 3} 2573-2575$.

23 Magill SB, Raff H, Shaker JL, Brickner RC, Knechtges TE, Kehoe ME \& Findling JW. Comparison of adrenal vein sampling and computed tomography in the differentiation of primary aldosteronism. Journal of Clinical Endocrinology and Metabolism $2001 \mathbf{8 6}$ 1066-1071.

24 Young WF. Primary aldosteronism: update on diagnosis and treatment. Endocrinologist 19977 213-221.

25 Bravo EL, Tarazi RC, Dustan HP, Fouad FM, Textor SC, Gifford RW et al. The changing clinical spectrum of primary aldosteronism. American Journal of Medicine $1983 \mathbf{7 4}$ 641-651.

26 Jose A \& Kaplan NM. Plasma renin activity in the diagnosis of primary aldosteronism: failure to distinguish primary aldosteronism from essential hypertension. Archives of Internal Medicine $1969123141-145$.

27 Lins PF \& Adamson U. Plasma aldosterone-plasma renin activity ratio: a simple test to identify patients with primary hyperaldosteronism. Acta Endocrinologica $1986113564-569$.

28 McKenna TJ, Sequeira SJ, Heffernan A, Chambers J \& Cunningham S. Diagnosis under random conditions of all disorders of the renin-angiotensin-aldosterone axis, including primary hyperaldosteronism. Journal of Clinical Endocrinology and Metabolism $199173952-957$.

29 Hiramatsu K, Yamada T, Yukimura Y, Komiya I, Ichikawa K, Ishihara $\mathrm{M}$ et al. A screening test to identify aldosterone-producing adenoma by measuring plasma renin activity: results in hypertensive patients. Archives of Internal Medicine $1981 \mathbf{1 4 1}$ 1589-1593.

30 Young WF Jr, Hogan MJ, Klee GG, Grant CS \& van Heerden JA. Primary aldosteronism: diagnosis and treatment. Mayo Clinic Proceedings 199065 96-110.

31 Weinberger MH \& Fineberg NS. The diagnosis of primary aldosteronism and separation of two major subtypes. Archives of Internal Medicine 1993153 2125-2129.

32 Gordon RD. Primary aldosteronism. Journal of Endocrinological Investigations $1995 \mathbf{1 8}$ 495-511.

33 Litchfield WR \& Dluhy RG. Primary aldosteronism. Endocrinology and Metababolism Clinics of North America 199524 593-612.

34 Young WF. Pheochromocytoma and primary aldosteronism: diagnostic approaches. Endocrinology and Metababolism Clinics of North America 199726 801-827.

35 Lyons DF, Kem DC, Brown RD, Hanson CS \& Carollo ML. Single dose captopril as a diagnostic test for primary aldosteronism. Journal of Clinical Endocrinolgy and Metabolism 198357 892-896.

36 Hambling C, Jung RT, Gunn A, Browning MCK \& Bartlett WA. Re-evaluation of the captopril test for the diagnosis of primary hyperaldosteronism. Clinical Endocrinology 199236 499-503.

37 Vallotton MB. Primary aldosteronism. Part I. Diagnosis of primary hyperaldosteronism. Clinical Endocrinology 199645 47-52.

38 Kem DC, Weinberger MH, Mayes DM \& Nugent CA. Saline suppression of plasma aldosterone in hypertension. Archives of Internal Medicine $1971 \mathbf{1 2 8} 380-386$.

39 Grim CE, Weinberger MH, Higgins JT \& Kramer NJ. Diagnosis of secondary forms of hypertension. Journal of the American Medical Association $19772371331-1335$.

40 Young WF \& Klee GG. Primary aldosteronism. Diagnostic evaluation. Endocrinology and Metababolism Clinics of North America $198817367-395$.
41 Streeten DHP, Tomycz N \& Anderson GH. Reliability of screening methods for the diagnosis of primary aldosteronism. American Journal of Medicine 197979 403-413.

42 Holland OB, Brown H, Kuhnert L, Fairchild C, Risk M \& GomezSanchez CE. Further evaluation of saline infusion for the diagnosis of primary aldosteronism. Hypertension $19846717-723$.

43 Agharazii M, Douville P, Grose JH \& Lebel M. Captopril suppression versus salt loading in confirming primary aldosteronism. Hypertension 200137 1440-1443.

44 Phillis JL, Walther MM, Pezzullo JC, Rayford W, Choyke PL, Berman AA, Linehan WM, Doppman JL \& Gill JR. Predictive value of preoperative tests in discriminating bilateral adrenal hyperplasia from an aldosterone-producing adrenal adenoma. Journal of Clinical Endocrinolgy and Metabolism $2000 \quad \mathbf{8 5}$ $4526-4533$.

45 Rossi GP, Sacchetto A, Chiesura-Corona M, De Toni R, Gallina M, Feltrin GP \& Pessina AC. Identification of the etiology of primary aldosteronism with adrenal vein sampling in patients with equivocal computed tomography and magnetic resonance findings: results in 104 consecutive cases. Journal of Clinical Endocrinolgy and Metabolism 200186 1083-1090.

46 World Health Organization - International Society of Hypertension Guidelines for the Management of Hypertension. Journal of Hypertension 199917 151-183.

47 Fishman LM, Kuchal O, Liddle GW, Michelakis AM, Gordon RD \& Chick WT. Incidence of primary aldosteronism in uncomplicated essential hypertension. A prospective study with elevated aldosterone secretion and suppressed plasma renin activity used as diagnostic criteria. Journal of the American Medical Association 1968205 497-502.

48 Shiroto H, Ando H, Ebitani I, Hara M, Numazawa K, Kanamura S et al. Normotensive primary aldosteronism. American Journal of Medicine 198069 603-606.

49 Kono T, Ikeda F, Oseko F, Imura H \& Tanimura H. Normotensive primary aldosteronism: report of a case. Journal of Clinical Endocrinology and Metabolism 198152 1009-1013.

50 Vantyghem MC, Ronci N, Provost F, Ghulam A, Lefebvre J, Jeunemaitre $\mathrm{X}$ et al. Aldosterone-producing adenoma without hypertension: a report of two cases. European Journal of Endocrinology $1999141279-285$.

51 Chidiac RM \& Aron DC. Incidentalomas. A disease of modern technology. Endocrinology and Metabolism Clinics of North America $199726233-253$.

52 Ross NS \& Aron DC. Hormonal evaluation of the patient with an incidentally discovered adrenal mass. New England Journal of Medicine $1990323401-405$.

53 Kloos RT, Gross MD, Francis IR, Korobkin M \& Shapiro B. Incidentally discovered adrenal masses. Endocrine Reviews $1995 \mathbf{1 6}$ 460-484.

54 Ambrosi B, Passini E, Re T \& Barbetta L. The clinical evaluation of silent adrenal masses. Journal of Endocrinological Investigations 199720 90-107.

55 Gross MD \& Shapiro B. Clinically silent adrenal masses. Journal of Clinical Endocrinology and Metabolism 199377 885-888.

56 Cook DM \& Loriaux DL. The incidental adrenal mass. American Journal of Medicine $1996 \mathbf{1 0 1} 88-94$.

Received 29 October 2001

Accepted 7 January 2002 